\title{
Quantification of Pfiesteria piscicida growth and encystment parameters using a numerical model
}

\author{
J. T. Anderson ${ }^{1,2, *}$, R. R. Hood $^{1}$, X. Zhang ${ }^{1}$ \\ ${ }^{1}$ University of Maryland Center for Environmental Science, Horn Point Laboratory, PO Box 775, Cambridge, Maryland 21613, USA \\ ${ }^{2}$ Present address: Skidaway Institute of Oceanography, 10 Ocean Science Circle, Savannah, Georgia 31411, USA
}

\begin{abstract}
In the past decade, there has been growing interest in understanding the physiological ecology and life cycle of toxic forms of Pfiesteria piscicida. However, transformations among noninducible (NON-IND; formerly described as nontoxic) stages have received less attention despite the fact that NON-IND stages are found in nature and may be ecologically important as prey and predators. NON-IND stages are also mixotrophic and have the ability to retain and utilize prey chloroplasts in a process termed 'kleptoplastidic mixotrophy'. Quantifying growth, grazing and encystment rates from P. piscicida laboratory experiments is confounded by the interrelationship between mixotrophy and life stage transformations. By fitting a numerical model to a laboratory experiment on NON-IND P. piscicida, we were able to isolate the potential mechanisms that cause encystment and speculate on the interrelationship between adverse conditions (i.e. low light and limiting prey) and life stage transformations. The structure of the laboratory experiment allowed for the estimation of several growth and encystment parameters including grazing rates, gross growth and assimilation efficiencies, as well as the retention time of chloroplasts. Model results suggest a link between encystment and mixotrophic ability. Furthermore, the model results suggest that encystment rates and gross growth and assimilation efficiencies calculated from the model are lower than expected.
\end{abstract}

KEY WORDS: Pfiesteria piscicida $\cdot$ Harmful algal blooms $\cdot$ Numerical models $\cdot$ Kleptochloroplastidy $\cdot$ Mixotrophy $\cdot$ Life history transformations $\cdot$ Resting stages

\section{INTRODUCTION}

Many dinoflagellates have life stages that include cysts (Rengefors \& Anderson 1998), sexual forms such as gametes and planozygotes (Pfiester \& Anderson 1987), or benthic amoebae (Popovsky \& Pfiester 1982, Burkholder \& Glasgow 1995). Transformations to these stages can affect the persistence and distribution of a population, and ecosystem dynamics (Tyler et al. 1982, Blanco 1995, Kremp \& Heiskanen 1999). Similarly, many dinoflagellates are considered mixotrophic with a variety of complex nutritional strategies that could also affect ecosystem dynamics (Stoecker 1998, 1999, Stickney et al. 2000). However, few investigations examine the interactions of mixotrophic behavior and life stage transformations, despite the fact that some of the species that have complex life histories are also considered mixotrophs (i.e. Gyrodinium uncatenum:
Coats et al. 1984, Bockstahler \& Coats 1993; Dinophysis spp.: Jacobson \& Andersen 1994, Giacobbe \& Gangemi 1997). For this investigation, we use the dinoflagellate Pfiesteria piscicida as a model species because it has a complex life history (Burkholder \& Glasgow 1995) and is considered a mixotroph (Lewitus et al. 1999).

In the past decade, there has been growing interest in understanding the physiological ecology of Pfiesteria piscicida and its potential effects on fisheries. In mid-Atlantic rivers and estuaries, $P$. piscicida sometimes co-occurs with fish kills (Burkholder et al. 1995). While fish kills can be caused by a variety of physical and biological stressors (e.g. hypoxia or anoxia, pollutants; Lowe et al. 1991, Paerl et al. 1998), some life stages of $P$. piscicida produce toxins that can directly kill fish (Burkholder et al. 1995). As a result, the life cycle and factors affecting transformation to and from 
these toxic $P$. piscicida have been studied extensively (Burkholder et al. 1995, Steidinger et al. 1996, Burkholder \& Glasgow 1997a).

Recently, Burkholder et al. (2001) developed new terminology to describe differences among forms of Pfiesteria piscicida based on their toxin-producing ability. The revised terminology separates $P$. piscicida into 'actively toxic' (TOX-A), 'potentially toxic' (TOXB) and 'non-inducible' (NON-IND) forms based on their response to exposure to fish. The majority of research on $P$. piscicida has focused on TOX-A and/or TOX-B forms, therefore little is known about the 'NON-IND' forms.

The life cycle and life stage triggers of a NON-IND Pfiesteria piscicida strain were documented in Anderson et al. (2003, this issue). In the presence of certain prey densities and irradiance combinations, a small subset of the life stages found in Burkholder \& Glasgow (1997a) were observed, including NON-IND zoospores (NIZs), 2 types of cysts, and possibly sexual intermediate stages. One of the cysts, Cyst A, formed from the NIZs only when recently fed algal prey, but regardless of light intensity. The second type of cyst, Cyst B, formed from NIZs only when recently fed and apparently only when exposed to $>24 \mathrm{~h}$ of complete darkness (Anderson et al. 2002).

The complex interactions between mixotrophy of Pfiesteria piscicida zoospores and transformations to cysts confound the interpretation of growth, grazing and encystment parameters from laboratory data alone. The objective of this study is to examine the $P$. piscicida laboratory experiment described by Anderson et al. (2002) in the context of a numerical model which provides a quantitative description of the factors that affect mixotrophy and life history transformations in NON-IND $P$. piscicida. By fitting the model to the laboratory data, several physiological parameters, including encystment rates, can be estimated. Also, the NON-IND strain's reduced life cycle is a more tractable modeling problem and can be used as the basis for expanding to toxic forms.

\section{MATERIALS AND METHODS}

Laboratory experiment. The laboratory methods are reported in Anderson et al. (2002). In brief, the laboratory experiment was designed as a $2 \times 3$ factorial of light intensity and prey density (the cryptophyte Storeatula major) with 3 replicates. The light intensities tested were moderate irradiance $\left(83 \mu \mathrm{mol}\right.$ photons $\mathrm{m}^{-2}$ $\mathrm{s}^{-1}$ ) with a 12:12 h light:dark photoperiod ('Light') and complete darkness ('Dark'). Algal prey densities tested were no prey (the control), 5000 cells ml $^{-1}$ (a 2:1 prey:Pfiesteria ratio) and 12500 cells ml$^{-1}$ (a 5:1 ratio).
Flasks were sampled at the initiation of the experiment and on the first day of the experiment, and then every other day for $13 \mathrm{~d}$.

Numerical model. The model was developed using the $\mathrm{C}++$ programming language and is based on the kleptochloroplastidic mixotroph model of Stickney et al. (2000). The model contains a prey stock (P) that represents the cryptophyte Storeatula major, a kleptoplastidic mixotroph stock (M) that represents Pfiesteria piscicida zoospores, and 2 sink stocks (CA and $\mathrm{CB}$ ) that represent the 2 cyst stages (Cyst A and Cyst B) described in Anderson et al. (2002). Bacterial, nutrient and detritus pools were not specifically modeled, because the laboratory experiment was run in nutrient-replete conditions, and bacteria and detritus were not quantitatively measured. The model simulates population abundance as cells $\mathrm{ml}^{-1}$ through time using a 4th-order Runge-Kutta solver.

Model assumptions and equations. Model parameters and their units are presented in Table 1. The change in prey stock $(P)$ is modeled as follows based on the prey stocks defined in Stickney et al. (2000).

$$
\frac{\mathrm{d} P}{\mathrm{~d} t}=\mu_{\mathrm{mp}} P-R_{\mathrm{p}} P-\alpha P M
$$

The stock increases at a constant growth rate of $\mu_{\mathrm{mp}}$ in the presence of light. The prey stock also respires at a constant rate $\left(R_{\mathrm{p}}\right)$. Although most models acknowledge saturating prey concentrations in the form of a rectilinear or Michaelis-Menten functional response (Frost 1972), this model assumes the prey concentrations encountered are below saturation (Stoecker unpubl.), and incorporates a linear functional response with slope $\alpha$ (the clearance rate). In the presence of a predator, the prey population is grazed at a rate of $\alpha P$ (prey cells zoospore $\mathrm{e}^{-1} \mathrm{~d}^{-1}$ ). The total amount of prey grazed is calculated by multiplying the individual grazing rate by the number of zoospores $(M)$.

The change in zoospore stock $(M)$ is based on gains due to heterotrophic grazing and kleptochloroplastidy, and losses due to respiration and senescence terms, and 1-way transformations to Cyst A and Cyst B.

$$
\frac{\mathrm{d} M}{\mathrm{~d} t}=\mathrm{CE}_{\mathrm{pm}} \alpha P M-R_{\mathrm{m}} M-S_{\mathrm{m}} M-T_{\mathrm{mcA}} M-T_{\mathrm{mcB}} M
$$

The zoospore stock increases by converting ingested algal prey into zoospore biomass with an efficiency of $\mathrm{CE}_{\mathrm{pm}}$ (the conversion efficiency). $\mathrm{CE}_{\mathrm{pm}}$ is based on formulations that utilize assimilation efficiency (AE) and gross growth efficiency (GGE; Harris et al. 2000). In these formulations, the relationship between net growth $\left(G_{\text {net }}\right)$ of an organism and the amount of ingested material $(I)$ is described as linear with a slope equal to the organism's gross growth efficiency and intercept equal to basal respiration: 


$$
G_{\text {net }}=\mathrm{GGE} \times I-R_{\mathrm{m}}
$$

Net growth consists of 4 components: total ingested material $(I)$, egestion $(E)$ and respiration $\left(R_{\mathrm{i}}\right.$ and $R_{\mathrm{m}}$; Harris et al. 2000).

$G_{\text {net }}=\left(I-E-R_{\mathrm{i}}\right)-R_{\mathrm{m}}=I-(1-\mathrm{AE}) I-(\mathrm{AE}-\mathrm{GGE}) I R_{\mathrm{m}}$

Of the ingested material $(I)$, a fraction is assimilated (digested) with an efficiency of $\mathrm{AE}$, while the remaining fraction (1 - AE) is egested. Of the ingested material that is assimilated, a portion is used to cover respiration, while the other fraction is used for growth. The respiration component is separated into a basal metabolism $\left(R_{\mathrm{m}}\right)$ component that is independent of ingestion and an active metabolism $\left(R_{\mathrm{i}}\right)$ component that is proportional to ingestion (Steele \& Mullin 1977, Harris et al. 2000).

According to Stoecker (1998), kleptochloroplastidy may enhance an organism's growth by recycling nutrients that would otherwise be excreted. Stickney et al. (2000) interpreted this enhancement as a reduction in ingestion-related respiration $\left(R_{\mathrm{i}}\right)$ that can be achieved by modifying the conversion efficiency as a function of available prey and irradiance (i.e. as a function of the potential contribution of mixotrophy). In cases where prey is abundant, the numerical model presented here also uses this assumption. Therefore, the quantity of $\mathrm{CE}_{\mathrm{pm}}$ is determined by the amount of irradiance and is represented as follows.

$$
\mathrm{CE}_{\mathrm{pm}}=\mathrm{GGE}_{\mathrm{pm}}+\left(\mathrm{AE}_{\mathrm{pm}}-\mathrm{GGE}_{\mathrm{pm}}\right) f(L)
$$

where $\mathrm{GGE}_{\mathrm{pm}}$ is the gross growth efficiency of the zoospore (in units of [zoospore cells][prey cell $]^{-1}$ ), $\mathrm{AE}_{\mathrm{pm}}$ is the assimilation efficiency of the zoospore (in units of [zoospore cells][prey cell] ${ }^{-1}$ ), and $f(L)$ is a binary response based on the presence or absence of irradiance. In the presence of irradiance, $f(L)$ is 1 and the [ $\left(\mathrm{AE}_{\mathrm{pm}}-\right.$ $\left.\mathrm{GGE}_{\mathrm{pm}}\right)$ ] term is expressed. The $\mathrm{GGE}_{\mathrm{pm}}$ terms cancel and $\mathrm{CE}_{\mathrm{pm}}$ becomes $\mathrm{AE}_{\mathrm{pm}}$. In the absence of irradiance, the $\left[\left(\mathrm{AE}_{\mathrm{pm}}-\mathrm{GGE}_{\mathrm{pm}}\right) f(L)\right]$ term is zero and $\mathrm{CE}_{\mathrm{pm}}$ is simply GGE pm. .

To correct for the differential mass of algal prey and zoospore cells, reported values of $\mathrm{GGE}_{\mathrm{pm}}$ and $\mathrm{AE}_{\mathrm{pm}}$ were normalized to dimensionless values based on nitrogen content per cell. Cellular nitrogen content for both the prey and zoospore stage were based on measured values by Li (1998) for the same algal prey, and for a similar-sized mixotrophic dinoflagellate, Gymnodinium galatheanum (= Gyrodinium galatheanum; Li 1998). The nitrogen contents used were $9.41 \mathrm{pg}$ (prey cell) ${ }^{-1}$ and $18.73 \mathrm{pg}$ (zoospore cell) ${ }^{-1}$, yielding a conversion factor from (zoospore cells) (prey cell) ${ }^{-1}$ to dimensionless units of 1.99 .

In the Stickney et al. (2000) model, the mixotroph components can only benefit from kleptochloroplasts when actively grazing. However, several studies indicate that kleptochloroplastidy can also occur for a short period after prey is depleted (Skovgaard 1998, Lewitus et al. 1999). Since the majority of this experiment's laboratory data involves low concentrations or absence of algal prey, the assumptions of Stickney et al. (2000) need to be modified to fit the experiment. To include kleptochloroplastidic behavior after prey is depleted, it is assumed that there is an exhaustible plastid pool in the zoospore. The plastid pool is not modeled quantitatively as mass, but as a measure of how long the plastid pool will remain functional within the zoospore ( $\left.T_{\text {plastid }}\right)$. Therefore, just after prey is depleted, the

Table 1. Pfiesteria piscicida. Parameter descriptions for the numerical model. Values providing the best model fit to the experimental data as determined by calibration tests. 'Light' and 'Dark' simulations were analyzed and ranked independently. A rank of ' 1 ' indicates the model output is most sensitive to that parameter and a rank of '10' or ' 11 ' indicates the model output is least

\begin{tabular}{|c|c|c|c|c|c|}
\hline \multirow{2}{*}{ Description } & \multirow[t]{2}{*}{ Symbol } & \multirow[t]{2}{*}{ Value } & \multirow[t]{2}{*}{ Units } & \multicolumn{2}{|c|}{ Sensitivity rank } \\
\hline & & & & Dark & Light \\
\hline Gross growth efficiency for zoospores & $\mathrm{GGE}_{\mathrm{pm}}$ & 0.24 & dimensionless & 1 & 5 \\
\hline Basal metabolism of the zoospore & $R_{\mathrm{m}}$ & 0.12 & $\mathrm{~d}^{-1}$ & 2 & 7 \\
\hline Clearance rate of the zoospore & $\alpha$ & 0.0009 & $\mathrm{ml}$ zoospore $\mathrm{e}^{-1} \mathrm{~d}^{-1}$ & 3 & 4 \\
\hline Kleptochloroplast retention time & $T_{\text {plastid }}$ & 4.30 & days & 4 & 1 \\
\hline Zoospore senescence & $S_{\mathrm{m}}$ & 0.18 & $\mathrm{~d}^{-1}$ & 5 & 3 \\
\hline Respiration of the prey & $R_{\mathrm{p}}$ & 0.12 & $\mathrm{~d}^{-1}$ & 6 & 9 \\
\hline Transformation rate to Cyst B & $\tau_{\mathrm{mcB}}$ & $0.00255^{\mathrm{a}}$ & cysts zoospore ${ }^{-1} \mathrm{~d}^{-1}$ & 7 & 11 \\
\hline Transformation rate to Cyst A & $\tau_{\mathrm{mcA}}$ & $0.0013^{\mathrm{a}}$ & cysts zoospore ${ }^{-1} \mathrm{~d}^{-1}$ & 8 & 10 \\
\hline Threshold prey concentration & $\mathrm{TH}_{\mathrm{m}}$ & 100 & prey cells $\mathrm{ml}^{-1}$ & 9 & 8 \\
\hline Assimilation efficiency for zoospores & $\mathrm{AE}_{\mathrm{pm}}$ & 0.33 & dimensionless & $10^{\mathrm{b}}$ & 2 \\
\hline Maximum growth rate of the prey & $\mu_{\mathrm{mp}}$ & 1.42 & $\mathrm{~d}^{-1}$ & $10^{\mathrm{b}}$ & 6 \\
\hline
\end{tabular}
sensitive to that parameter 
$T_{\text {plastid }}$ parameter begins with a value equal to a specified maximum retention time $\left(T_{\text {retention }}\right)$. From this point, the $T_{\text {plastid }}$ parameter decreases linearly so that the relative size and effectiveness of the plastid pool is based on how long the zoospore population has retained the plastids. The entire plastid pool is exhausted by the end of the retention time.

In the presence of irradiance and after prey concentrations are depleted, a recently obtained plastid pool allows the zoospore population to grow at a rate comparable to basal metabolism $\left(R_{\mathrm{m}}\right)$. This results in a net daily respiration of zero and is consistent with the conceptual models of kleptochloroplastidic mixotrophs described by Stoecker (1998). However, as the plastid pool decreases, the gain due to mixotrophy also decreases so that metabolic costs eventually overcome the gain through photosynthesis. When the plastid pool is completely exhausted, the zoospore stock decreases at an additional rate $S_{\mathrm{m}}$ (the senescence rate). The stock can also decrease through encystment to Cyst A and Cyst B ( $T_{\mathrm{mcA}} M$ and $\left.T_{\mathrm{mcB}} M\right)$.

Changes in cyst stocks ( $C A$ and $C B$ ) are only through 1 -way transformations from zoospores (Anderson et al. 2003).

$$
\begin{aligned}
\frac{\mathrm{d} C A}{\mathrm{~d} t} & =T_{\mathrm{mcA}} M \\
\frac{\mathrm{d} C B}{\mathrm{~d} t} & =T_{\mathrm{mcB}} M
\end{aligned}
$$

Encystment to Cyst A does not appear to be a response to adverse conditions, since it occurs regardless of light intensity and only while actively feeding and for a short time after feeding (Anderson et al. 2002). Rather, encystment to Cyst A may require energy and/or a cofactor that is only acquired from recently ingested prey. As an alternative, transformation to Cyst A may be stimulated by optimal conditions, possibly as the result of a sexual cycle. In some dinoflagellates, sexuality is stimulated in optimal conditions (Anderson et al. 1983, Kremp \& Heiskanen 1999), and in toxic Pfiesteria piscicida, zoospores can form gametes while actively feeding on fish fragments (Burkholder et al. 1992, Mallin et al. 1995). In cases where fish are not present, algal prey may also stimulate sexuality.

The laboratory experiment did not distinguish between gametes, planozygotes and zoospores because they are difficult to positively identify from epifluorescence microscopy. For simplicity, the numerical model did not attempt to include these stages as separate stocks, and refers to these stages collectively as 'zoospores', since our observations suggest the zoospore stage is the most common flagellated stage. Furthermore, the model assumes that transformations to Cyst A require energy and/or a co-factor from recently ingested prey (Anderson et al. 2002). There- fore, transformations to Cyst A only occur when the zoospore population is actively feeding or is retaining plastids. The realized encystment rate to Cyst A $\left(T_{\text {mcA }}\right)$ is dependent upon the maximum encystment rate $\left(\tau_{\mathrm{mcA}}\right)$ and the amount of time left until the plastids lose functionality ( $\left.T_{\text {plastid }}\right)$. The maximum encystment rate occurs when plastids are just acquired $\left(T_{\text {plastid }}=T_{\text {retention }}\right)$ and then decreases linearly as chloroplast functionality decreases, eventually ceasing at $T_{\text {plastid }}=0$. Note that the rate of plastid loss is the same regardless of light intensity, while the benefits of the retained chloroplasts are dependent on light intensity.

$$
T_{\mathrm{mcA}}=\tau_{\mathrm{mcA}} \frac{T_{\text {plastid }}}{T_{\text {retention }}}
$$

In contrast to Cyst A, encystment to Cyst B appears to be a response to adverse conditions such as complete darkness and prey depletion (Anderson et al. 2003). These environmental stressors may affect the ability to gain energy from stolen chloroplasts and as a result may trigger encystment to Cyst $B$. In the numerical model, transformations to Cyst B occur when the zoospore population has recently fed and has depleted the algal prey, is retaining plastids and has been exposed to at least $24 \mathrm{~h}$ of complete darkness. The model determines when conditions are favorable for encystment through 'if' statements and a variable that keeps track of the amount of time exposed to darkness. When conditions are met for encystment, the magnitude of the encystment rate to Cyst B is determined in the same way as for Cyst A.

Parameter calibration and sensitivity analysis. Calibrated parameter values for the model were determined by iteratively choosing values within a realistic range and testing how well the model fit the laboratory data. Quantification of the best model fit was determined using the Modeling Performance Index software developed by F. Villa ${ }^{1}$. The performance tests used were the Error Composition, and the DentBlackie linear regression tests. The Error Composition test scored (between 0 and 1) the magnitude of sum of squares of differences between the model results and experimental data. Higher scores mean lower sum of squares. The second test, Dent-Blackie linear regression, scored the $F$-value probability (between 0 and 1 ) and tested the hypothesis that the regression line of model data versus experimental data would have a slope of 1 and an intercept of zero (Dent \& Blackie 1979). Higher scores translated to a better fit. Within

${ }^{1} \mathrm{~F}$. Villa (1997) The modeling performance evaluation software. http://iee.umces.edu/ villa/svp/. Maryland International Institute for Ecological Economics, University of Maryland, Solomons 
each test, scores were calculated for each stock (prey, zoospores, Cyst A and Cyst B) and averaged for a total test score. The average of both test scores was used to determine a global score. Parameter sets that maximized the global score were used.

Specific treatment combinations from the laboratory experiment were used to isolate and calibrate the parameters of the model. The 'Dark' and 'Light' prey control data sets were used to solve $R_{\mathrm{p}}$ and $\mu_{\mathrm{mp}}$, respectively. The zoospore's basal metabolism and senescence terms $\left(R_{\mathrm{m}}\right.$ and $\left.S_{\mathrm{m}}\right)$ as well as $T_{\text {retention }}$ were simultaneously solved using both 'Dark' and 'Light' Pfiesteria piscicida control data sets. $\mathrm{GGE}_{\mathrm{pm}}, \mathrm{AE}_{\mathrm{pm}}, \alpha$ and $T H_{\mathrm{m}}$ were simultaneously solved using both the 'Dark' and 'Light' 2:1 prey:Pfiesteria data sets. $\tau_{\mathrm{mcA}}$ and $\tau_{\mathrm{mcB}}$ were solved for each replicate within each treatment combination using the parameter values solved above.

Model sensitivity was determined by perturbing each parameter by $\pm 10 \%$ and measuring the increase in sum of squares of differences. Since the sensitivity of some parameters is dependent upon irradiance, sensitivity was analyzed independently in 'Light' and 'Dark' conditions. A sensitivity index was calculated as the normalized sum of squares increase for a single parameter to the maximum increase observed over all parameters. Ranks were assigned to each parameter accordingly, where a sensitivity rank of '1' indicates the model results are most sensitive to that parameter.

Statistical analysis of encystment rates. $\tau_{\mathrm{mcA}}$ and $\tau_{\mathrm{mcB}}$ were obtained from the 'best-fit' calibrations for each replicate of each treatment combination. Differences between treatment combinations were analyzed using the 1-way Kruskal-Wallis nonparametric and Wilcoxon rank sum tests provided by SAS (version 7.0; SAS 1998). Significant differences between treatment combinations were determined at the 0.05 critical level.

\section{RESULTS}

\section{Calibration and sensitivity analysis}

The parameter values and sensitivity ranks are described in Table 1. Calibrated values were associated with global scores ranging from approximately 0.84 to 0.99. Unique maximum global scores were found in all parameter calibrations, including calibrations that required simultaneous solutions. The sensitivity analysis indicated that in complete darkness, the model is most sensitive to $\mathrm{GGE}_{\mathrm{pm}}$ and $R_{\mathrm{m}}$. In the dark, the model is least sensitive to $\mathrm{AE}_{\mathrm{pm}}$ and $\mu_{\mathrm{mp}}$. In the presence of light, the model is most sensitive to $T_{\text {retention }}$ and $\mathrm{AE}$, but is least sensitive to $\tau_{\mathrm{mcA}}$ and $\tau_{\mathrm{mcB}}$. Since the formulation of $\mathrm{CE}_{\mathrm{pm}}$ in the numerical model involves a switch be- tween $\mathrm{GGE}_{\mathrm{pm}}$ and $\mathrm{AE}_{\mathrm{pm}}$ as a function of irradiance, it appears the model was most sensitive to $\mathrm{CE}_{\mathrm{pm}}$ regardless of light intensity.

\section{Model output compared with laboratory data}

In general, the numerical model predicted the patterns observed in the laboratory. The zoospore laboratory data appeared to be divided into 3 phases (Fig. 1): active grazing and growth (Days 0 to 1 ; only in fed treatments), persistence and/or low respiration losses (Days 1 to 5), and a dramatic decrease in abundance (Days 5 to 13). In fed treatments, for both the 'Light' and 'Dark' treatments, zoospores grazed the algal prey to low or undetectable concentrations by the first day. Still, the model incorporated the differential growth of the prey in the 'Light' versus 'Dark' treatment. The inclusion of an exhaustible plastid pool in the numerical model's structure recreated patterns that were similar to the 3 phases observed in the laboratory. In this section, each phase is compared with the numerical model's results.

In the growth and grazing phase (Days 0 to 1 ), the model's linear response to prey availability (with a slope of $\alpha=0.0009$ ) appeared to overestimate the net growth of zoospore stocks in the 'Light' exposed 5:1 prey:Pfiesteria treatment (Fig. 1g). However, the model output underestimated zoospore growth in the 'Dark' exposed 5:1 prey:Pfiesteria treatment. The model output predicted that Cyst A formation increased at its maximum rate $\left(\tau_{\mathrm{mcA}}\right)$ during this phase. Encystment to Cyst B did not occur during this phase.

In Phase 2 (Days 1 to 6 for the fed treatments; Days 1 to 5 for the unfed control), the 'Light' exposed model output predicted a zigzagged alternation between respiration loss in the dark $\left(R_{\mathrm{m}}=0.12\right)$ and photosynthetic gain. This zigzag pattern was a direct result of the 12:12 h light:dark photoperiod. However, the basal metabolism value, calibrated using the control's 'Dark' treatment, appeared to be an overestimate of the actual zoospore loss rates for both 'Dark' fed treatments (Fig. 1d,g). Cyst A continued to form during this period, but at a continuously decreasing rate. Based on the model assumptions, this decreasing rate was related to the plastid pool degradation. Cyst B began to form during this period and decreased at a continuous rate similar to Cyst $\mathrm{A}$.

In Phase 3 (Days 6 to 13 for fed treatments; Days 5 to 13 for the unfed control), the modeled zoospore stocks decreased at an accelerated rate due to both the basal metabolism $\left(R_{\mathrm{m}}=0.12\right)$ and the senescence rate $\left(S_{\mathrm{m}}=0.18\right)$. The sum of these 2 loss terms $(0.12+0.18=$ 0.30 ) adequately represented the rate of decline in all treatments. Cyst A and Cyst B formation ceased during this period. 

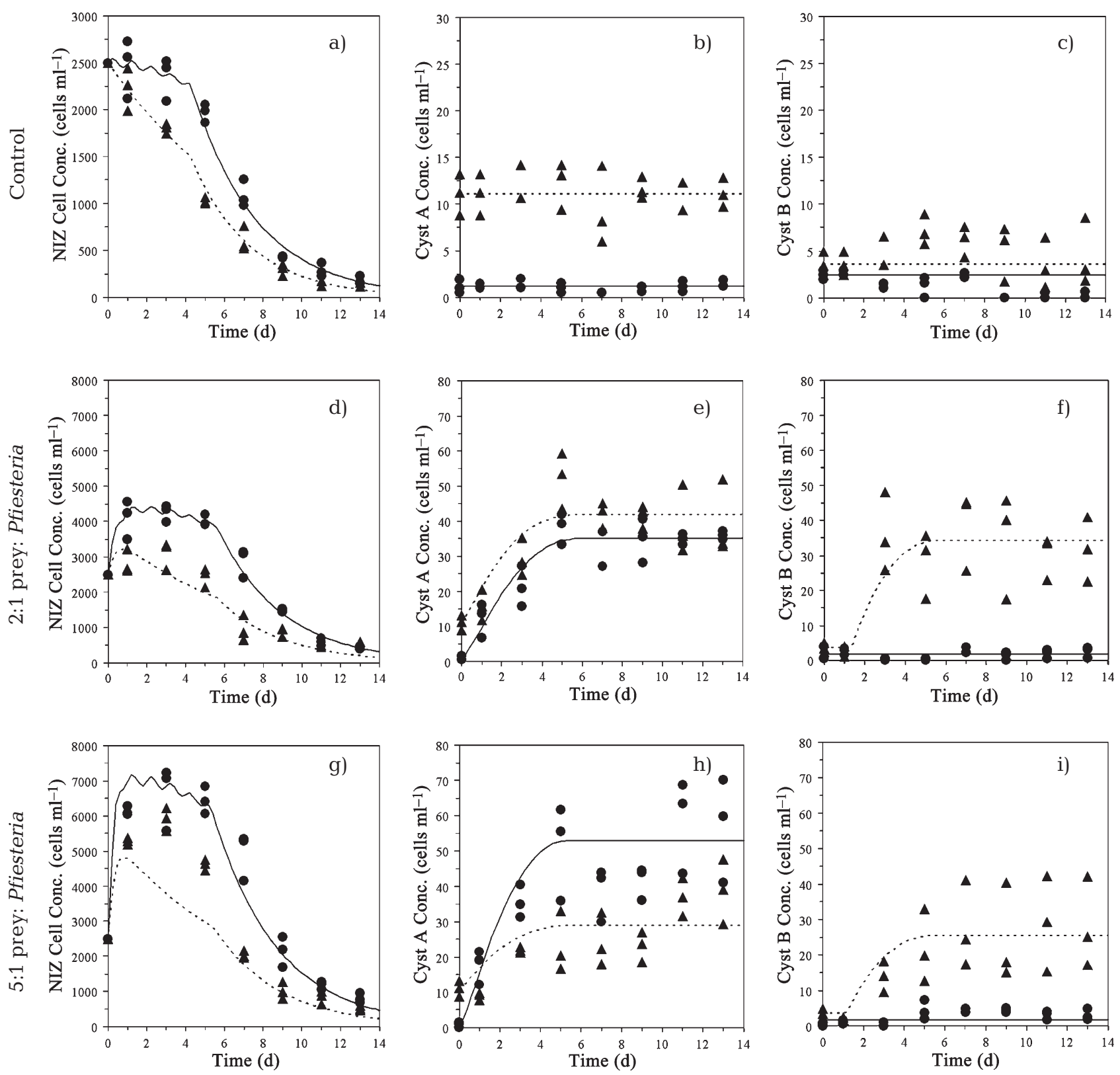

Fig. 1. Pfiesteria piscicida. 'Best fit' model compared with experimental data. Model results are represented by lines, experimental data are represented by symbols (3 replicates for each time period). Columns represent concentrations of the 3 life stages: non-inducible zoospores (NIZs), Cyst A, and Cyst B. Rows represent different prey concentration treatments: control,

2:1 prey:Pfiesteria ratio, 5:1 prey:Pfiesteria ratio. 'Light' treatments: $\bullet$, continuous line; and 'Dark' treatments: $\mathbf{\Delta}$, dashed line

\section{Encystment rates}

Encystment rates obtained from the parameter calibration are presented in Fig. 2. For the control treatment, the calibrated encystment rates to Cyst A were zero. Maximum encystment rates for Cyst A in fed treatments were less than $0.35 \%$ of the zoospore population per day (Fig. 2). However, 'Dark' encystment was significantly higher in the 2:1 treatment than in the 5:1 treatment. In the 'Light' exposed treatments, encystment was not significantly different.

The calibrated encystment rates to Cyst B were 0 for the control and all 'Light' exposed treatments. Maximum encystment rates for Cyst B in fed treatments were less than $0.60 \%$ of the zoospore population per day (Fig. 2). There was no significant difference between the encystment rates of the 2:1 prey:Pfiesteria and the 5:1 prey:Pfiesteria treatments. 

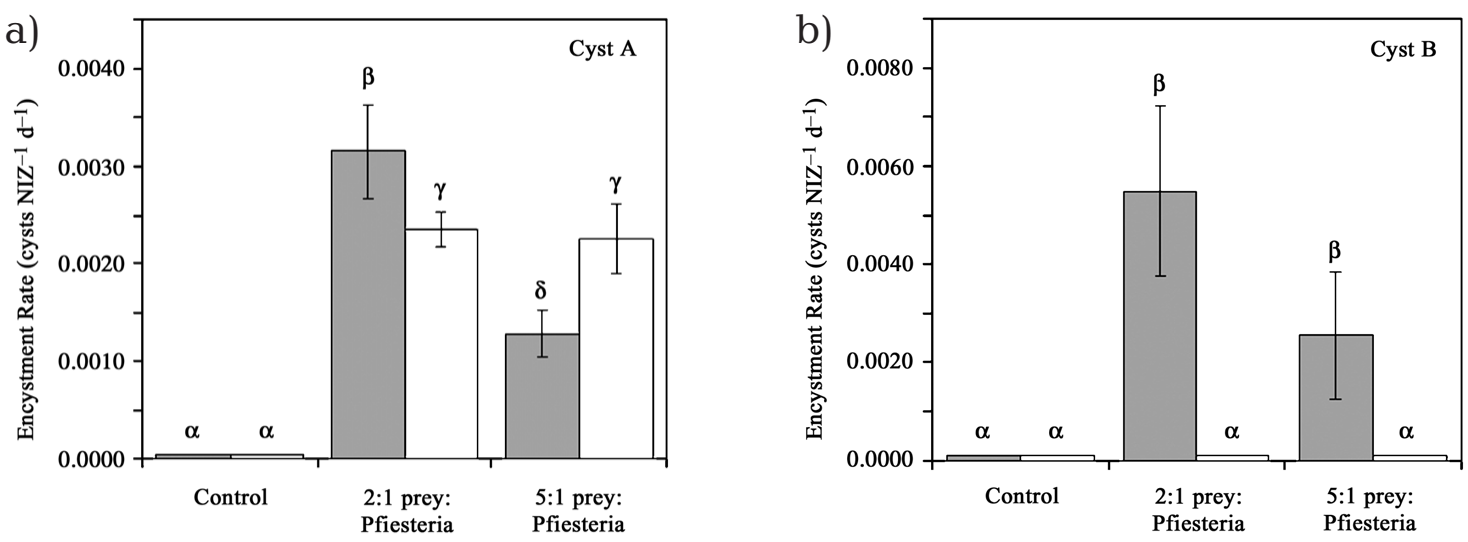

Fig. 2. Pfiesteria piscicida. Encystment rates (cysts zoospore $\mathrm{e}^{-1} \mathrm{~d}^{-1}$; mean $\pm \mathrm{SD}$ ) for each prey concentration and irradiance ('Dark': grey bars, 'Light': white bars). Treatment combinations with the same Greek letter are not significantly different at the 0.05 level

\section{DISCUSSION}

Differences in the dynamics of light- and darktreated flasks were observed in the first $6 \mathrm{~d}$ of the experiment, during the 'growth and grazing' and 'persistence and/or low respiration losses' phases described in 'Results'. According to the model structure, the cause of this difference is due to photosynthetic carbon fixation that covers respiration in the 'Light' treatments. Still, respiration in the fed 'Dark' treatments was consistently overestimated and dramatically affected the predictive ability of the model. A possible explanation is that the parameter values or model assumptions were unrealistic. Other explanations may include the ability of Pfiesteria piscicida zoospores (in darkness) to reduce cellular respiration and/or delay senescence through the use of an internal storage not considered in the model or through reducing the energy spent searching for prey.

Fitting a model to a single laboratory experiment (with 3 replicates) can influence and potentially bias the results. Still, it appears that most parameter values determined from the calibration are within realistic ranges. For example, the algal growth rate $\left(\mu_{\mathrm{mp}}=1.42 \mathrm{~d}^{-1}\right)$, basal metabolisms $\left(R_{\mathrm{p}}=R_{\mathrm{m}}=0.12\right.$ $\left.\mathrm{d}^{-1}\right)$ and zoospore senescence rate $\left(S_{\mathrm{m}}=0.18 \mathrm{~d}^{-1}\right)$ agree with parameter values used for other models (Fasham et al. 1990, Stickney et al. 2000). A maximum plastid retention time of $\sim 4 \mathrm{~d}$ is also within the range of other kleptochloroplastidic mixotrophs (Stoecker et al. 1988, Fields \& Rhodes 1991, Skovgaard 1998). Although maximum grazing rates could not be determined with non-saturating prey concentrations, observed initial grazing rates $(\alpha P)$ from each prey treatment were between 4.5 and 11.25 prey cells zoospore $\mathrm{e}^{-1} \mathrm{~d}^{-1}$, which are also within realistic ranges.
Gross growth efficiency $\left(\mathrm{GGE}_{\mathrm{pm}}=0.24\right)$ was within realistic ranges, though slightly lower than the average, for purely heterotrophic organisms (Conover 1978, Straile 1997). The assimilation efficiency $\left(\mathrm{AE}_{\mathrm{pm}}=0.33\right)$ calculated from the model is lower than expected for purely heterotrophic organisms (75\% for zooplankton; Conover 1978). However, kleptochloroplastidic organisms may have lower assimilation rates than purely heterotrophic organisms. Defining assimilation efficiency as the fraction of ingested material absorbed by the organism (Harris et al. 2000), the low value could imply that there is considerable egestion or expulsion of consumed material. Since kleptochloroplastidic organisms cannot retain chloroplasts indefinitely, a possibility may be egestion or expulsion of aging or nonfunctional chloroplasts. Lewitus et al. (1999) found that Pfiesteria piscicida retains functional chloroplasts inside the food vacuole. Keeping chloroplasts in the food vacuole could make it easier to expel used chloroplasts. However, there is no direct evidence of egestion, expulsion of aging or nonfunctional chloroplasts in P. piscicida or other kleptochloroplastidic organisms (Stoecker \& Silver 1990).

Encystment rates to both cysts were considerably lower than expected. At maximum rates of less than 0.35 and $0.60 \%$ of the zoospore population per day for Cyst A and Cyst B respectively, it would take between 17 and 29 d for 1000 zoospores to produce 100 cysts of either type. Encystment fractions in plankton species are highly variable, ranging from $<1$ to $>30 \%$ (Anderson et al. 1985, Agbeti \& Smol 1995). However, the low encystment rates observed here could be an artifact of extended laboratory rearing. Several studies have also observed lower encystment rates in laboratory conditions (Anderson et al. 1985, Jensen \& Moestrup 1997). Furthermore, the adherent qualities of the cysts observed in this Pfiesteria piscicida strain complicate the 
transferring of samples by selecting for motile, noncyst-forming individuals.

However, if the observed encystment rates are similar to those in natural populations, the low values suggest that cyst formation in Pfiesteria piscicida populations will not dramatically affect dynamics at small timescales. Still, these cysts, especially the resistant Cyst A (Anderson et al. 2003), may play important roles as bloom initiators through cyst germination. Therefore, relatively high concentrations of these cysts may occur where blooms reoccur or where currents can accumulate cysts to form 'seed beds'. Also, Cyst B populations may be more abundant in regions where light penetration is minimal, such as humic rich rivers or estuaries.

Differences between the model output and laboratory data in the 'Dark' fed treatments could reflect limitations in the model structure. For example, zoospores exposed to continuous darkness may be able to alter their behavior by reducing basal metabolism and/or delaying senescence through the use of an internal storage that is not considered in the model. 'Dark' treated zoospores may also modify their behavior by reducing the energy spent searching for prey. Though prey foraging was not quantitatively measured, qualitative observations do not suggest that zoospores exposed to complete darkness swim at slower speeds or search in a different pattern.

\section{CONCLUSIONS}

The numerical model was able to extract important physiological parameters from complex laboratory data with multiple life stages and kleptochloroplastidic behavior. The majority of estimated parameters appear to be within realistic ranges and suggest that the assumptions of the model were adequate. The low assimilation efficiency for Pfiesteria piscicida zoospores suggests that egestion or expulsion of ingested material is high. A possible explanation is that $P$. piscicida zoospores (and potentially other kleptochloroplastidic mixotrophs) may expel nonfunctional or aging kleptochloroplasts, though there is no evidence of this behavior. The magnitudes of encystment rates to Cyst A and Cyst B are lower than expected and may only affect population dynamics in conditions that accumulate these cysts.

A major assumption of this model involves the kleptochloroplastidic nature of Pfiesteria piscicida. Although research has been conducted on kleptochloroplastidic dinoflagellates (Skovgaard 1998, Stoecker 1999), little is known about the physiology and functional role of sequestered chloroplasts. The model assumptions concerning an exhaustible plastid pool are a simplification of a more complex physiological mechanism controlled by several internal and external factors, and models require better resolution of plastid pool dynamics as well as a better understanding of how irradiance could affect the utilization of these plastid pools.

Acknowledgements. This research was funded by a Horn Point Laboratory Fellowship, HPL Small Grants Award, ECOHAB and NSF. Thanks for the anonymous reviewers' comments provided on an earlier draft. Special thanks to Dr. Diane Stoecker, Jason Adolf, Matthew Johnson and Daniel Gustafson for their guidance with the laboratory experiment. Thanks to Dr. Joann Burkholder for her input on life history stages and Dr. Karen Steidinger for providing the cultures. Also, thanks to Holly Bowers, Torstein Teng and Dr. David Oldach for testing the cyst samples with molecular probes.

\section{LITERATURE CITED}

Agbeti MD, Smol JP (1995) Chrysophyte population and encystment patterns in two Canadian lakes. J Phycol 31:70-78

Anderson DM, Chisholm SW, Watras CJ (1983) Importance of life cycle events in the population dynamics of Gonyaulax tamarensis. Mar Biol 76(2):179-189

Anderson DM, Coats DW, Tyler MA (1985) Encystment of the dinoflagellate Gyrodinium uncatenum: temperature and nutrient effects. J Phycol 21(2):200-206

Anderson JT, Stoecker DK, Hood RR (2003) Formation of two types of cysts by a mixotrophic dinoflagellate, Pfiesteria piscicida. Mar Ecol Prog Ser 246:95-104

Blanco J (1995) Cyst production in four species of neritic dinoflagellates. J Plankton Res 17(1):165-182

Bockstahler KR, Coats DW (1993) Spatial and temporal aspects of mixotrophy in Chesapeake Bay dinoflagellates. J Eukaryot Microbiol 40(1):49-60

Burkholder JM, Glasgow HB (1995) Interactions of a toxic estuarine dinoflagellate with microbial predators and prey. Arch Protistenkd 145:177-188

Burkholder JM, Glasgow HB (1997a) Pfiesteria piscicida and other Pfiesteria-like dinoflagellates: behavior, impacts, and environmental controls. Limnol Oceanogr 42(5/2): 1052-1075

Burkholder JM, Glasgow HB (1997b) Trophic controls on stage transformations of a toxic ambush-predator dinoflagellate. J Eukaryot Microbiol 44(3):200-205

Burkholder JM, Noga EJ, Hobbs CH, Glasgow HB (1992) New 'phantom' dinoflagellate is the causative agent of major estuarine fish kills. Nature 358(6385):407-410

Burkholder JM, Glasgow HB, Hobbs CH (1995) Fish kills linked to a toxic ambush-predator dinoflagellate: distribution and environmental conditions. Mar Ecol Prog Ser 124: 43-61

Burkholder JM, Glasgow HB, Deamer-Melia NJ, Springer J, Parrow MW, Zhang C, Cancellieri PJ (2001) Species of the toxic Pfiesteria complex and the importance of functional type in data interpretation. Environ Health Perspect 109: $667-686$

Coats DW, Tyler MA, Anderson DM (1984) Sexual processes in the life cycle of Gyrodinium uncatenum (Dinophyceae): a morphogenetic overview. J Phycol 20(3):351-361

Conover RJ (1978) Transformation of organic matter. In: Kinne O (ed) Marine Ecology, Vol 4. Dynamics. John Wiley \& Sons, New York 
Dent JB, Blackie MJ (1979) Systems simulations in agriculture. Applied Science Publishers, Essex

Fasham MJR, Ducklow HW, McKelvie SM (1990) A nitrogenbased model of plankton dynamics in the oceanic mixed layer. J Mar Resh 48:591-639

Fields SD, Rhodes RG (1991) Ingestion and retention of Chroomonas spp. (Cryptophyceae) by Gymnodinium acidotum (Dinophyceae). J Phycol 27:525-529

Frost BW (1972) Effects of size and concentration of food particles on the feeding behavior of the marine planktonic copepod Calanus pacificus. Limnol Oceanogr 17(6): 805-815

Giacobbe MG, Gangemi E (1997) Vegetative and sexual aspects of Dinophysis pavillardi (Dinophyceae). J Phycol 33(1):73-80

Harris RP, Wiebe PH, Lenz J, Skjoldal HR, Huntley M (2000) ICES zooplankton methodology manual. Academic Press, New York

Jacobson DM, Andersen RA (1994) The discovery of mixotrophy in photosynthetic species of Dinophysis (Dinophyceae): light and electron microscopical observations of food vacuoles in Dinophysis acuminata, D. norvegica and two heterotrophic dinophysoid dinoflagellates. Phycologia 33(2):97-110

Jensen MØ, Moestrup $\varnothing$ (1997) Autecology of the toxic dinoflagellate Alexandrium ostenfeldii: life history and growth at different temperatures and salinities. Eur J Phycol 32(1):9-18

Kremp A, Heiskanen AS (1999) Sexuality and cyst formation of the spring-bloom dinoflagellate Scrippsiella hangoei in the coastal northern Baltic Sea. Mar Biol 134:771-777

Lewitus AJ, Glasgow HB, Burkholder JM (1999) Kleptoplastidy in the toxic dinoflagellate Pfiesteria piscicida (Dinophyceae). J Phycol 35:303-312

Li A (1998) Estimates of grazing by the mixotrophic dinoflagellate, Gyrodinium galatheanum, on cryptophyte populations in Chesapeake Bay. In: The feeding, physiology, and ecology of the mixotrophic dinoflagellate Gyrodinium galatheanum. PhD thesis, Chapter 6, University of Maryland Center for Environmental Science, Cambridge

Lowe JA, Farrow DRG, Pait AS, Arenstam SJ, Lavan EF (1991) Fish kills in coastal waters 1980-1989. Strategic Environmental Assessments Division. NOAA, Washington, DC

Mallin MA, Burkholder JM, Larsen LM, Glasgow HB (1995) Response of two zooplankton grazers to an ichthyotoxic estuarine dinoflagellate. J Plankton Res 17(2):351-363

Editorial responsibility: Otto Kinne (Editor), Oldendorf/Luhe, Germany
Paerl HW, Pickney JL, Fear JM, Peierls L (1998) Ecosystem responses to internal and watershed organic matter loading: consequences for hypoxia in the eutrophying Neuse River Estuary, North Carolina, USA. Mar Ecol Prog Ser 166:17-25

Pfiester LA, Anderson DM (1987) Dinoflagellate reproduction. In: Taylor FJR (ed) The biology of dinoflagellates. Blackwell Scientific Publications, Boston

Popovsky J, Pfiester LA (1982) The life-histories of Stylodinium sphaera Pascher and Cystodinedria inermis (Geitler) Pascher (Dinophyceae), two freshwater facultative predator-autotrophs. Arch Protistenkd 125:115-127

Rengefors K, Anderson DM (1998) Environmental and endogenous regulation of cyst germination in 2 freshwater dinoflagellates. J Phycol 34(4):568-577

SAS (1998) SAS Statistical Software version 7.0. SAS Institute, Cary, NC

Skovgaard, A (1998) Role of chloroplast retention in a marine dinoflagellate. Aquat Microb Ecol 15:293-301

Steele JH, Mullin MM (1977) Zooplankton dynamics. In: Goldberg ED (ed) The sea, ideas and observations on progress in the study of the seas. John Wiley, New York Steidinger KA, Burkholder JM, Glasgow HB, Hobbs CW, Truby E, Garrett J, Noga EJ, Smith SA (1996) Pfiesteria piscicida gen. et sp. nov. (Pfiesteriaceae fam. nov.), a new toxic dinoflagellate with a complex life cycle and behavior. J Phycol 32(1):157-164

Stickney HL, Hood RR, Stoecker DK (2000) The impact of mixotrophy on planktonic marine ecosystems. Ecol Model 125:203-230

Stoecker DK (1998) Conceptual models of mixotrophy in planktonic protists and some ecological and evolutionary implications. Eur J Protistol 34:281-290

Stoecker DK (1999) Mixotrophy among dinoflagellates. J Eukaryot Microbiol 46(4):397-401

Stoecker DK, Silver MW (1990) Replacement and aging of chloroplasts in Strombidium capitatum (Ciliophora: Oligotrichida). Mar Biol 107:491-502

Stoecker DK, Silver MW, Michaels AE, Davis LH (1988) Obligate mixotrophy in Laboea strobila, a ciliate which retains chloroplasts. Mar Biol 99:415-423

Straile D (1997) Gross growth efficiencies of protozoan and metazoan zooplankton and their dependence on food concentration, predator-prey weight ratio, and taxonomic group. Limnol Oceanogr 42(6):1375-1385

Tyler MA, Coats DW, Anderson DW (1982) Encystment in a dynamic environment: deposition of dinoflagellate cysts by a frontal convergence. Mar Ecol Prog Ser 7(2):163-178

Submitted: April 2, 2001; Accepted: July 18, 2002

Proofs received from author(s): December 19, 2002 